\title{
The health of "emerging adults" in Australia: freedom, risk and rites of passage
}

\author{
People transitioning to adulthood need more than medical finger-wagging
} Melissa S-L Kang
MBBS, MCH Senior Lecturer

Discipline of General Practice, University of Sydney, Sydney, NSW. melissa.kang@ sydney.edu.au

doi: 10.5694/mjal4.01409 $\mathrm{s}$ the end of November approaches, tens of thousands of secondary school leavers around Australia prepare for the annual celebration known as "Schoolies" ("Leavers" in Western Australia). This rite of passage for many young people involves travelling to certain destinations around the country or overseas to participate in organised parties and recreational activities.

Each year, Schoolies brings into focus two important adolescent health issues: acute alcohol-related harm and unwanted consequences of sexual activity. In Australia and the United States, young people who attend a Schoolies-like event expect to get drunk, and these expectations are usually met. ${ }^{1}$ Further, the incidence of binge drinking during Schoolies has not changed over time, and there is increasing gender convergence on patterns of intoxication. ${ }^{1,2}$ Significant proportions of intoxicated young people at Schoolies require transport to hospital for further care, ${ }^{3}$ and hospital data are likely to underestimate the extent of this problem. ${ }^{4}$ Fewer expect to have sex, but these expectations, when present, are also usually met, often with casual partners. ${ }^{1,5}$ As Schoolies expands to include international destinations such as Bali and Fiji, additional exposures to communicable diseases and pretravel vaccination need to be considered. ${ }^{6}$

For most young Australians, the end of secondary school coincides with entering adulthood. Turning 18 years old has significant legal implications: the right to vote, enter into contracts, purchase tobacco and alcohol, and consent to one's own medical treatment without the need for a mature-minor assessment, to name a few. This emancipation from childhood, symbolised for many by Schoolies, brings a new wave of health risks. The epidemiology is stark: morbidity and mortality are higher in young adults (up to 24 years) compared with younger adolescents, in Australia and overseas. ${ }^{7,8}$ In Australia, the death rate for 20-24-year-olds is almost four times greater than that for 12-14-year-olds and 1.4 times greater than that for 15-19-year-olds. ${ }^{7}$ Mental health disorders, chronic conditions, and notification rates for sexually transmitted infections and bloodborne viruses are all higher for 18-24-year-olds than for 12-17-year-olds. ${ }^{7}$ Globally, health-related behaviour, such as tobacco use, binge drinking and unprotected sex, and overweight and obesity increase in prevalence from adolescence to young adulthood. ${ }^{9}$

The unique health needs of young adults compared with younger adolescents have concerned youth health professionals for the past decade and a half, together with greater understanding of neurodevelopment in this age group. It has been suggested that subcortical systems of the adolescent brain mature earlier and faster than the prefrontal cortical systems that bring impulses under control. Independence-seeking behaviour that involves risk taking and peer-directed social interactions accelerates during puberty, while self-regulatory, cognitive processes rely on the relatively slower maturation of the prefrontal cortex, which continues until about 25 years of age. ${ }^{10}$ The widening gap between biological and psychosocial maturation is a phenomenon unique in human history that has arisen from economic, social and cultural factors. ${ }^{11}$ It is postulated that the later age at which young people take on social roles such as marriage, parenthood and employment, and the initiation of behaviour such as sexual activity and substance use during adolescence, have contributed to increased risk of sexually transmitted infections, substance misuse and mental disorders. ${ }^{11}$

The late adolescent (17-20 years) has reached peak intellectual capacity, a clearer sense of identity and significant emotional maturity. There is a deepening awareness of broader social and cultural norms and values and what they mean to the individual. We begin to see the adoption of, or resistance to, dominant discourses about health, illness and sexuality. In this context, the medicalisation of emotional distress, ${ }^{12}$ sexuality and alcohol and drug use can be a double-edged sword. Public health discourse invariably constructs alcohol consumption and sexual activity in young people as negative, and supports the binary view that these very human activities only occur in one of two ways: safely, or with risk to health. Social scientists and enlightened public health and health promotion practitioners, as well as young people, recognise what has been described as "the determined obtuseness of public health when it addresses the risks and pleasures of everyday life".13

In summary, young adults are in a unique place in the lifespan and landscape of contemporary society. By epidemiological measures, there is a call to action for academics, health professionals and policymakers. Research that focuses on the "emerging adult", and that incorporates qualitative and quantitative methods, would deepen our understanding of this critical transitional period. Viewing young adults' health issues through a medical or public health lens alone, and ignoring the competing discourses between pleasure and freedom on the one hand, and health, risk and safety on the other, will limit our ability to engage with young people and help them become makers of their own destinies. 


\section{Competing interests: No relevant disclosures.}

Provenance: Commissioned; externally peer reviewed.

1 Jones S, Barrie L, Robinson L. The schoolies experience: the role of expectancies, gender roles and social norms of recent school leavers. Wollongong: Centre for Health Initiatives, University of Wollongong, 2011.

2 Salom C, Watts M, Kinner S, Young D. Schoolies week in perspective: studies of alcohol, drug and risk-taking behaviour. Of Substance: the National Magazine on Alcohol, Tobacco and Other Drugs 2005; 3(1): 26-28.

3 Hutton A, Cusack L, Zannettino L. Building public policy to support young people in reducing alcohol-related harm when partying at Schoolies Festivals. Aust J Prim Health 2012; 18: 96-100.

4 Egerton-Warburton D, Gosbell A, Wadsworth A, et al. Survey of alcoholrelated presentations to Australasian emergency departments. Med J Aust 2014; 201: 584-587.

5 Maticka-Tyndale E, Herold ES, Oppermann M. Casual sex among Australian schoolies. J Sex Res 2003; 40: 158-169.
6 Huang GKL, Bond KA, Hewitt NH, Johnson PDR. Measles: an important cause of fever and rash in a returned traveller. Med J Aust 2014; 201 605-606.

7 Australian Institute of Health and Welfare. Young Australians: their health and wellbeing 2011. Canberra: AlHW, 2011. (AlHW Cat. No. PHE 140.)

8 Irwin CE Jr. Young adults are worse off than adolescents [editorial]. J Adolesc Health 2010; 46: 405-406.

9 Patton GC, Coffey C, Cappa C, et al. Health of the world's adolescents: a synthesis of internationally comparable data. Lancet 2012; 379: 1665-1675.

10 Casey B, Jones RM, Somerville LH. Braking and accelerating of the adolescent brain. J Res Adolesc 2011; 21: 21-33.

11 Patton GC, Viner R. Pubertal transitions in health. Lancet 2007; 369: $1130-1139$.

12 Jureidini JN. Let children cry. Med J Aust 2014; 201: 612-613.

13 Keane $\mathrm{H}$. Intoxication, harm and pleasure: an analysis of the Australian National Alcohol Strategy. Crit Public Health 2009; 19: 135-142. 